\title{
Investigations on dry sliding of laser cladded aluminum bronze
}

\author{
Hannes Freiße $e^{1, *}$, Anika Langebeck ${ }^{1}$, Henry Köhler ${ }^{1}$, Thomas Seefeld ${ }^{1}$, and Frank Vollertsen ${ }^{1,2}$ \\ 1 BIAS-Bremer Institut für angewandte Strahltechnik GmbH, Klagenfurter Str. 2, 28359 Bremen, Germany \\ 2 University of Bremen, Bibliothekstraße 1, 28359 Bremen, Germany
}

Received 18 March 2016 / Accepted 14 June 2016

\begin{abstract}
The aim of this study was to investigate the tribological behaviour of laser cladded aluminum bronze tool surfaces for dry metal forming. In a first part of this work a process window for cladding aluminum bronze on steel substrate was investigated to ensure a low dilution. Therefore, the cladding speed, the powder feed rate, the laser power and the distance between the process head and the substrate were varied. The target of the second part was to investigate the influence of different process parameters on the tribological behaviour of the cladded tracks. The laser claddings were carried out on both aluminum bronze and cold work tool steel as substrate materials. Two different particle sizes of the cladding powder material were used. The cladding speed was varied and a post-processing laser remelting treatment was applied. It is shown that the tribological behaviour of the surface in a dry oscillating ball-on-plate test is highly dependent on the substrate material. In the third part a deep drawing tool was additively manufactured by direct laser deposition. Furthermore, the tool was applied to form circular cups with and without lubrication.
\end{abstract}

Key words: Dry metal forming, Aluminum bronze, Dry sliding, Ball-on-plate test, Laser cladding

\section{Introduction}

The vision of avoiding lubricants in metal forming contributes an approach to establish green technology in mass production. This idea of sustainable production in metal forming is summarized by the concept of dry metal forming. It provides the possibility to improve production technology regarding environmental and economic aspects. State of research in dry metal forming is based on laboratory conditions and at this point, it is not possible to exert dry metal forming in industrial mass production [1].

The direct contact between the sheet and the tool during dry processing in metal forming causes high load and wear [2]. Aluminum bronze as a tool material provides advantages for forming tools, in particular for cold forming of high alloy austenitic steel due to its excellent friction property and high load capacity [3]. Several authors have already investigated dry sliding behaviour of aluminum bronze. Experiments on ultrafine-grained bulk material showed that grain refinement can improve the wear behaviour and reduce the friction coefficient in dry sliding against 100Cr6 steel. The adhesive wear tendency depended on the mechanical properties caused by applying an equal channel angular extrusion process [4].

\footnotetext{
*Corresponding author: freisse@bias.de
}

Within investigations on cast aluminum bronze it could be shown that wear behaviour highly depends on the aluminum content. The counter body was steel C45E. More wear and a higher coefficient of friction were observed by using an alloy with a lower aluminum content [5]. It has also been shown that friction coefficient and wear were reduced in dry rolling sliding against steel through electron beam surface remelting. The higher hardness in the surface was determined as the main cause for the improvement [6]. However, other studies in dry sliding of some tin and aluminum bronzes in a pin-on-disc test exhibited that tribological behaviour did not relate to mechanical properties like hardness [7]. A very close relation between the microstructure of aluminum bronzes and tribological properties in a dry block-on-ring test was found out [8].

In the field of surface engineering, laser materials processing offers various solutions like laser hardening, laser cladding or laser remelting. Aluminum bronze can be applied by laser cladding as a coating material for cold forming tools to reduce friction and particularly adhesive wear in forming of high alloy stainless steel like 1.4301 [9]. Today, adequate lubrication is necessary in metal forming for industrial mass production. Studies on friction and wear properties under the condition of boundary lubrication of plasma transfer arc and laser coatings of aluminum bronze powder revealed that the laser coatings showed a higher wear resistance [10]. The oscillating 
ball-on-plate test can be applied to characterize and to assess the behaviour of tool surfaces in dry sliding. The friction coefficient and wear of various material combinations can be evaluated very quickly and in a simple way by this test method [11]. By the German Association for Tribology, the different tribological tests can be structured in six categories of test methods with different levels of abstraction [12]. Category 1 represents the tribological testing of the real technical system and the other five categories involve simplified test methods with an increasing level of abstraction. The ball on plate test can be assigned to the category 6 with the highest level of abstraction. Extensive investigations about dry sliding of laser coated aluminum bronze determining the influence of major process parameters have not been carried out yet. In particular the influence of the dilution on the tribological behavior of laser cladded aluminum bronze tool surfaces for dry metal forming have not been carried out yet.

\section{Experimental details}

\subsection{Laser cladding and remelting}

Single layers of aluminum bronze were cladded by using a Trumpf HL4006D Nd:YAG-Laser with a wave length of $1064 \mathrm{~nm}$. To transmit the laser radiation into the process zone a fiber optic cable with a core diameter of $600 \mu \mathrm{m}$ was used. A collimation and a focusing optic, both with a focal length of $200 \mathrm{~mm}$ were deployed. The spot diameter of $2.5 \mathrm{~mm}$ was kept constant by defocusing. Therefore, the focus was positioning above the workpiece. The powder feeding machine GTV MF-PF-2/2 was included in the experimental set-up to deliver the powder material by using $7.5 \mathrm{~L} / \mathrm{min}$ argon gas at a pressure of 2.5 bar. The powder was applied coaxially by the cladding head YC50 from Precitec. Argon shielding gas was provided in the center with a rate of $14 \mathrm{~L} / \mathrm{min}$ and also coaxially with a rate of $7 \mathrm{~L} / \mathrm{min}$. The process head was tilted by an angle of $8^{\circ}$ in order to avoid back reflections into the optical fiber during cladding aluminum bronze. The investigations were carried out on substrate materials with the dimensions $60 \times 12 \times 20 \mathrm{~mm}^{3}$. The gas-atomized aluminum bronze powder with a chemical composition CuAl10Fe1 was used with particle size between $45 \mu \mathrm{m}$ and $125 \mu \mathrm{m}$ (in the following: "coarse powder").

For the application of laser generated surfaces for dry metal forming, following steps are necessary to understand the manufacturing process, the dry sliding behaviour and the dry metal forming process:

(I) Process development of laser cladding.

(II) Tribological investigations.

(III) Practical application of dry deep drawing.

Step I: The experiments were carried out on cold worked steel 1.2379. Process parameters were varied and the influence on the dilution, the catchment efficiency and the aspect ratio was determined. The specimens were weighted before and after cladding to determine the mass increase using a balance with a resolution within $\pm 0.01 \mathrm{~g}$. The catchment efficiency $\eta$ (1)

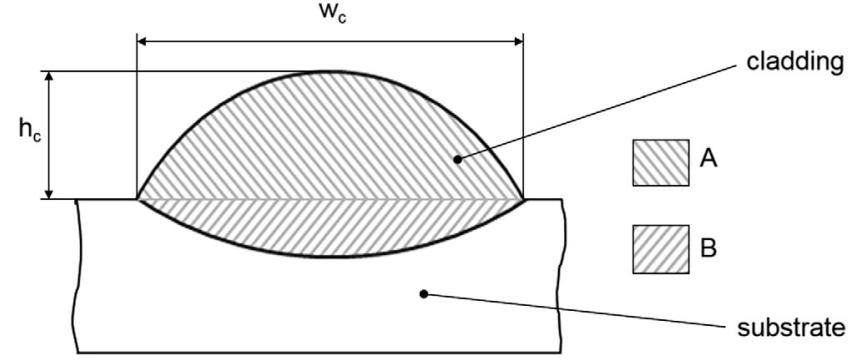

Figure 1. Geometry of a laser cladded track.

could be determined as a function of the mass increase $\Delta m$, the cladding speed $v_{\mathrm{c}}$, the powder feed rate $m_{\mathrm{g}}$ and the length $l$ of the cladded track:

$$
\eta=\left(\Delta m \times v_{\mathrm{c}}\right) /\left(m_{\mathrm{g}} \times l\right) .
$$

The aspect ratio of the cladding seam is defined as the ratio of width $w_{\mathrm{c}}$ and the height $h_{\mathrm{c}}$ of a track (Figure 1). The dilution DL (2) was calculated from the cross sections area $A$ and $B$ as follows:

$$
\mathrm{DL}=A / A+B .
$$

The laser power was varied between $1500 \mathrm{~W}$ and $4000 \mathrm{~W}$. Cladding speeds from $0.2 \mathrm{~m} / \mathrm{min}$ to $0.7 \mathrm{~m} / \mathrm{min}$ were applied. The powder feed rate was varied from $15 \mathrm{~g} / \mathrm{min}$ to $40 \mathrm{~g} / \mathrm{min}$. Commonly it is assumed that the working distance between the laser head and the substrate have a significant influence on the cladded tracks. The change of this distance can be influenced by the inaccuracy of the handling machine during the direct laser deposition process. The intrinsic inaccuracy of the CNC (Computer Numeric Control) handling machine used for these investigations is $\pm 10 \mu \mathrm{m}$. Therefore, investigations were carried out by variation of the distance between the laser head and the workpiece in a range of $\pm 2 \mathrm{~mm}$.

Step II: The influence of the process parameters on the tribological behaviour was examined. The laser power amounted to $3 \mathrm{~kW}$ and the powder feed rate was $20 \mathrm{~g} / \mathrm{min}$. For these experiments, in addition to the coarse powder, a smaller particle size between $5 \mu \mathrm{m}$ and $53 \mu \mathrm{m}$ (in the following: "fine powder") was used. Furthermore, in addition to the cold worked steel 1.2379 substrate, aluminum bronze CuAl10Ni5Fe4 acted as substrate material. The cladding speed was varied in a range from $0.5 \mathrm{~m} / \mathrm{min}$ to $2 \mathrm{~m} / \mathrm{min}$. And also a post-process remelting treatment of the clad was carried out with the same laser power intensity as applied for the cladding process. A remelting speed of $1 \mathrm{~m} / \mathrm{min}$ was applied.

Step III: A deep drawing tool was additively manufactured by direct laser deposition. Laser power of $3 \mathrm{~kW}$ was used. The depositing speed amounted to $0.5 \mathrm{~m} / \mathrm{min}$. The powder feed rate was $20 \mathrm{~g} / \mathrm{min}$. An increment of $0.75 \mathrm{~mm}$ was used for adjusting the layers in vertical direction. The overlapping increment in horizontal direction was $2 \mathrm{~mm}$. To additively manufacture the punch, the outer boundary was deposited by adjusting rings and the inner area was realized by linear tracks. The diameter of the punch amounted to $30 \mathrm{~mm}$ and the height 
was $70 \mathrm{~mm}$. The blank holder and the drawing die were manufactured by the vertical and horizontal arrangement of rings. The defined dimensions were realized by milling.

The additively manufactured tool was applied for forming cups. In Table 1, all process geometries and data and of the deep drawing experiments are summarized. The punch force $F_{\mathrm{P}}$ (3) was calculated in consideration of the punch diameter $d$, the sheet thickness $s$, the tensile strength of the sheet $R_{\mathrm{m}}$, the drawing ration $\beta$ and the maximum drawing ratio $\beta_{\max }$ as follows:

$$
\begin{aligned}
F_{\mathrm{P}}= & \pi \times(d+s) \times s \times R_{\mathrm{m}} \times 1.2 \\
& \times(\beta-1) /\left(\beta_{\max }-1\right) .
\end{aligned}
$$

To realize the motion of the deep drawing process a compression tension testing machine Z250 from the company Zwick Roell was applied. The machine had a maximum force of $250 \mathrm{kN}$. The lubricant Wisura ZO3060 was applied. The force and the motion of the process were transferred by a deep drawing guiding device to the deep drawing tool. The deep drawing guiding device and the parts of the deep drawing tool are shown in Figure 2. The blank holder force was applied by means of four helical compression springs and was set by adjusting the suspension travel.

\subsection{Tribological testing}

Oscillating ball-on-plate tests were used to determine tribological properties. A counter body made of high alloy steel 1.4301 with a hardness of 242 HV0.5 was used. The rod was shaped as calotte with a radius of $5 \mathrm{~mm}$. The normal load was varied between $5 \mathrm{~N}$ and $15 \mathrm{~N}$. The commercially available tribometer CETR UMT-3MT was integrated in a temperature regulated climate chamber to perform the test in constant environmental conditions. The humidity during the test was $40 \% \pm 1 \%$ and temperature was $24{ }^{\circ} \mathrm{C} \pm 1{ }^{\circ} \mathrm{C}$. The wear path was $10 \mathrm{~mm}$. The test specimen oscillated and the sliding speed was varied between $5 \mathrm{~mm} / \mathrm{s}$ and $15 \mathrm{~mm} / \mathrm{s}$. A sinusoidal speed profile was given in the oscillating test. The sliding distance amounted to $864 \mathrm{~m}$. The average of the friction coefficient was calculated through the software MatLab to receive the results for the linear movement between the turning points. The wear was determined by measuring the weight loss of the specimens using a balance with a resolution within $\pm 0.1 \mathrm{mg}$. The Hertzian stress at the beginning of the test was calculated. The surface pressure at the end of the test was determined by measuring the wear area of the ball.

\subsection{Metallographic analysis}

By metallographic cross sections the integrity of the cladded tracks was examined. The dilution was measured by means of the planimetry. The aspect ratio was determined. Vickers hardness HV0.5 measurements were carried out on the cross section, using a Leco MHT Series 200 semiautomatic hardness tester. The distances between measurement points were $250 \mu \mathrm{m}$. Electron probe microanalysis using
Table 1. Parameters and geometries of the deep drawing process.

\begin{tabular}{lcll}
\hline \multicolumn{1}{c}{ Parameter } & Value & Unit & \\
\hline Punch diameter & 30 & $\mathrm{~mm}$ & Given conditions \\
Height of the cup & 15 & $\mathrm{~mm}$ & \\
Sheet thickness & 0.5 & $\mathrm{~mm}$ & \\
Punch radius & 4 & $\mathrm{~mm}$ & \\
Drawing radius & 4 & $\mathrm{~mm}$ & \\
Tensile strength of the sheet & 750 & $\mathrm{MPa}$ & \\
Maximum drawing ratio & 2 & $/$ & \\
Blank holder pressure & 2.5 & $\mathrm{MPa}$ & \\
Forming speed & 10 & $\mathrm{~mm} / \mathrm{s}$ & \\
Blank diameter & 52 & $\mathrm{~mm}$ & Calculated \\
Inner diameter of the drawing & 31.4 & $\mathrm{~mm}$ & \\
Blank holder diameter & 31 & $\mathrm{~mm}$ & \\
Blank holder area & 905 & $\mathrm{~mm}$ & \\
Drawing clearance & 0.70 & $\mathrm{~mm}$ & \\
Drawing ratio & 1.73 & $/$ & \\
Punch force & 39 & $\mathrm{kN}$ & \\
Blank holder force & 2.3 & $\mathrm{kN}$ & \\
\hline
\end{tabular}

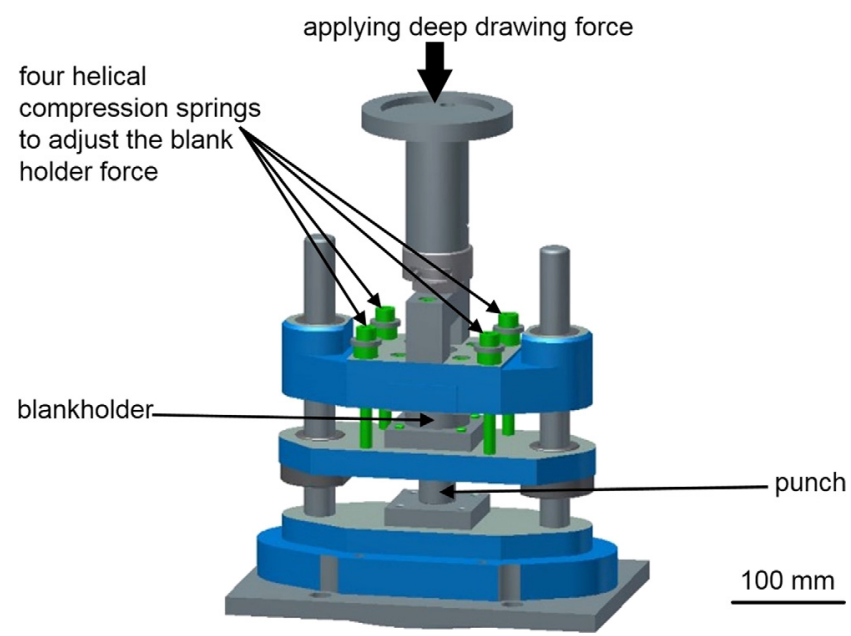

Figure 2. Deep drawing guiding device and the installed deep drawing tool.

wavelength dispersive X-ray spectroscopy (WDS) was applied to determine the chemical composition in the clad. The microprobe Jeol JXA-8200 was used.

\section{Results}

\subsection{Laser cladding of aluminum bronze on cold worked steel}

In Figure 3 the influence of the laser power on the catchment efficiency, the geometry of the tracks and the dilution is shown. It was found that the laser power neither significantly influenced the dilution nor the aspect ratio. In contrast, the catchment efficiency increased by applying a higher laser power. A catchment efficiency of $48 \%$ was measured by applying $1.5 \mathrm{~kW}$ laser power. Using a laser power of $4 \mathrm{~kW}$ resulted in a catchment efficiency of $75 \%$. 


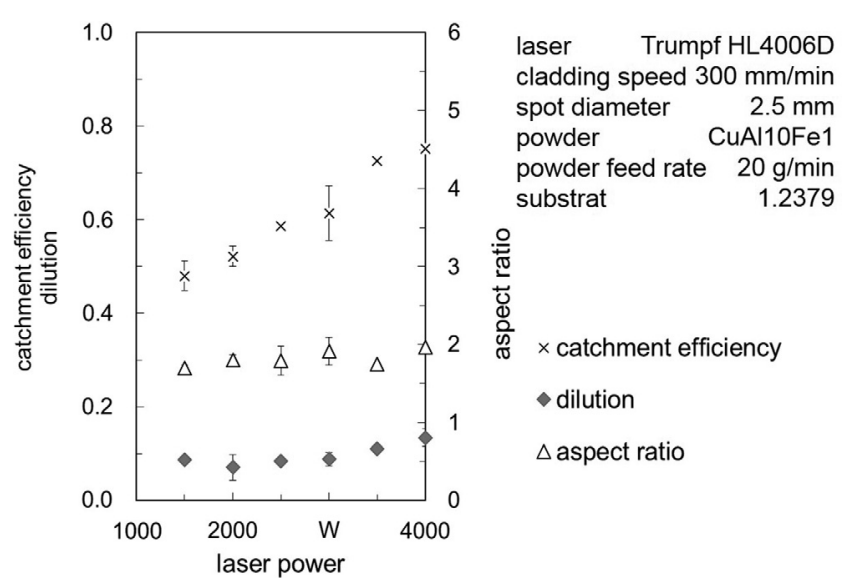

Figure 3. Influence of the laser power on the catchment efficiency, the dilution and the aspect ratio.

The results regarding the variation of the powder feed rate are summarized in Figure 4. It was observed that there was no significant influence of the powder feed rate on the catchment efficiency. However, there was a significant decrease of the aspect ratio observed when more powder per time was fed into the process. Applying a powder feed rate between $15 \mathrm{~g} / \mathrm{min}$ and $40 \mathrm{~g} / \mathrm{min}$ resulted in a low dilution between $3 \%$ and $9 \%$. It is to be noted that a high dilution of $21 \%$ was measured when a feed rate of $10 \mathrm{~g} / \mathrm{min}$ was used.

Varying of the cladding speed had an influence on the catchment efficiency as well on the dilution and the aspect ratio (Figure 5). In particular, there was a significant influence on the aspect ratio. Applying a cladding speed of $200 \mathrm{~mm} / \mathrm{min}$ resulted in an aspect ratio of 1.19 and in contrast an aspect ratio of 4.22 was measured when a cladding speed of $700 \mathrm{~mm} / \mathrm{min}$ was used. A higher catchment efficiency and less dilution were measured when a lower cladding speed was applied.

In Figure 6 the results of varying the distance between the laser processing head and the substrate material are summarized. The variation of the working distance between the laser processing head and the substrate showed that there was no significant influence on the catchment efficiency, the dilution and the aspect ratio when the variation was not higher than $\pm 1 \mathrm{~mm}$.

\subsection{Tribological reference tests on the substrate materials}

Tribological reference tests were carried out on both untreated substrates. Because of the wear of the calotte in the ball-on-plate test there was decrease of the surface pressure during tribological testing. At the beginning of the test, there was a high Hertzian stress. This depended on the substrate material and the normal force. Steel has a higher Young's modulus and this caused a higher Hertzian stress compared to the bronze substrate. The calculated values are given in Figure 7. At the end of the test, the calotte was deformed and the resulting surface pressure was about two magnitudes lower.

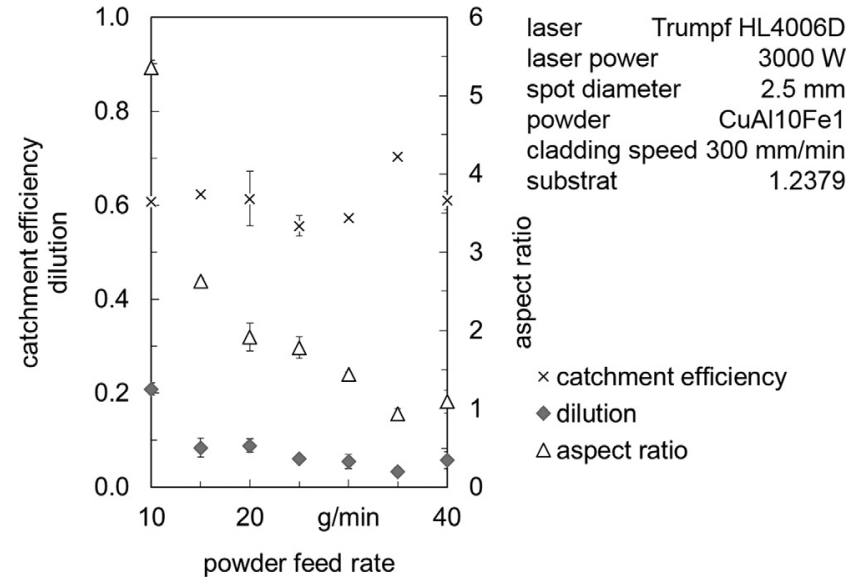

Figure 4. Influence of the powder feed rate on the catchment efficiency, the dilution and the aspect ratio.

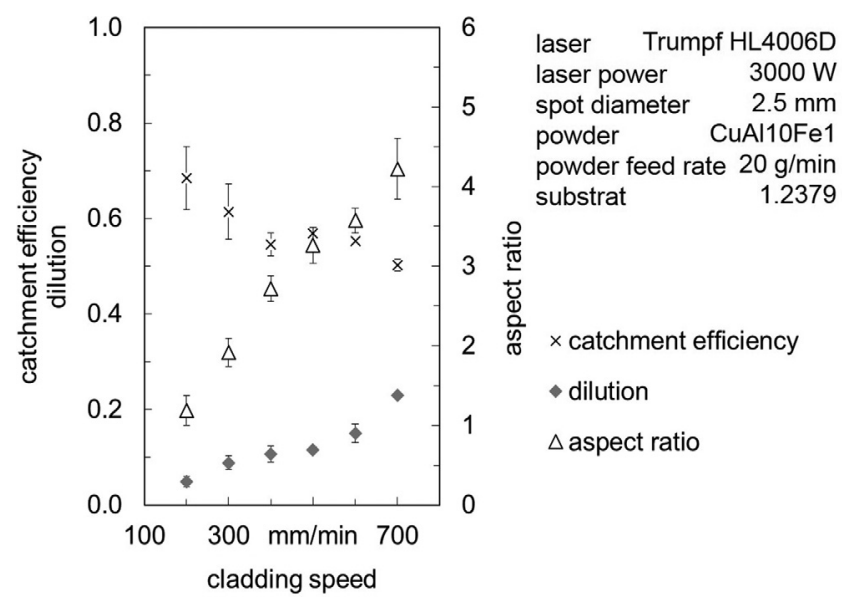

Figure 5. Influence of the cladding speed on the catchment efficiency, the dilution and the aspect ratio.

Figure 8 is showing the influence of the normal load on the friction coefficient and the wear. It is obvious that there is no significant influence of the normal load on the friction coefficient. In contrast, the wear highly depended on the normal load. A higher normal load resulted in significant more wear. It is to be noted that applying a normal force of $5 \mathrm{~N}$ the wear of bronze is twice as high as of steel. Applying a normal force of $15 \mathrm{~N}$ revealed that in this case the wear was equal for both substrates.

The influence of the sliding speed on the friction coefficient and the wear is shown in Figure 9. It was found that the friction coefficient showed the highest values by applying $10 \mathrm{~mm} / \mathrm{s}$ sliding speed. In contrast, by applying higher sliding speed the wear increased when steel acted as plate material and decreased when bronze acted as plate material.

\subsection{Tribological tests on clads}

Figure 10 is showing transient measurement data of the friction coefficient during the oscillating dry sliding test of 


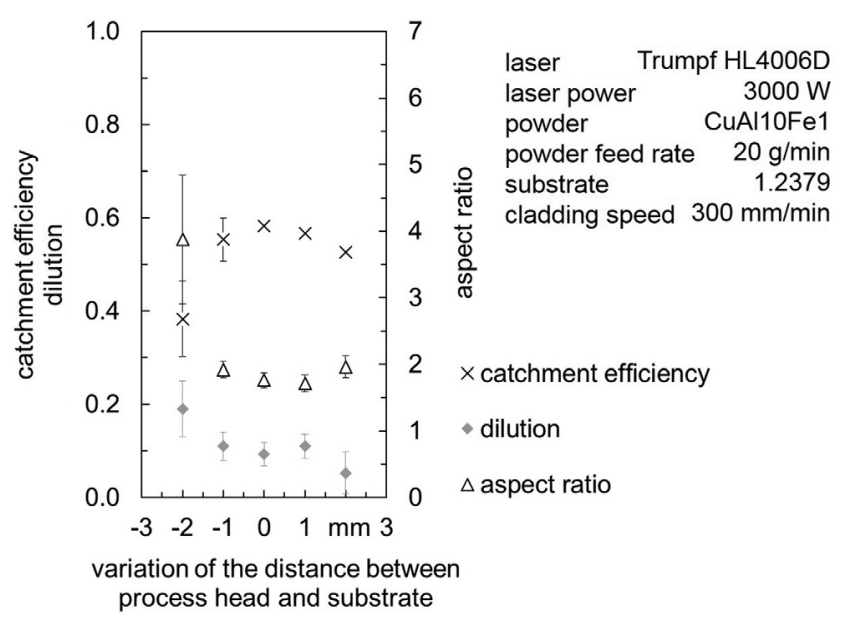

Figure 6. Influence of the working distance between the laser head and the substrate.

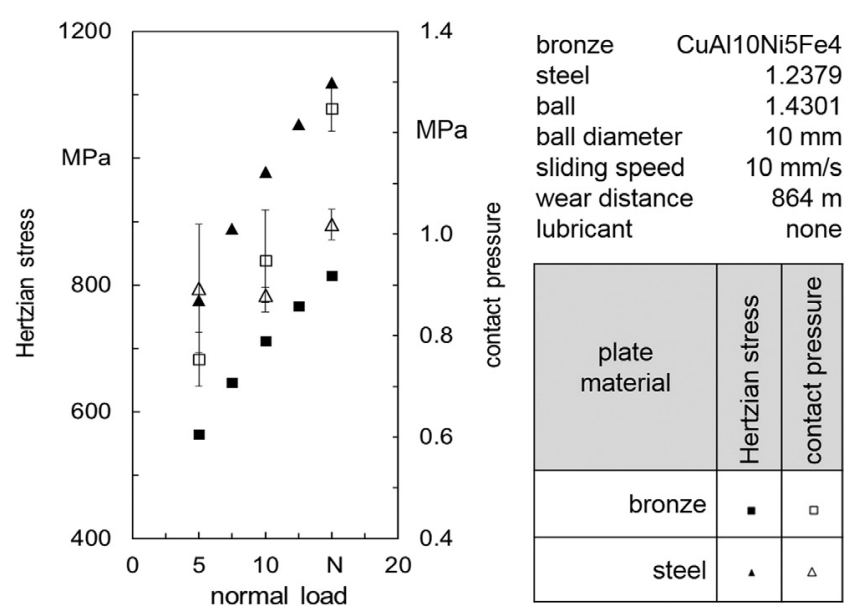

Figure 7. The calculated Hertzian stress at the beginning of the test and the contact pressure at the end of the test.

two specimens exemplarily. Both were cladded with a cladding speed of $1 \mathrm{~m} / \mathrm{min}$. In the case of steel substrate the friction coefficient had a slight rising tendency and a higher fluctuation towards increasing test duration. Lower fluctuation and an approximately constant course of the friction coefficient was observed in the case of aluminum bronze substrate.

An average friction coefficient was calculated for every specimen and the results are plotted in Figure 11. The resulting friction coefficients were much higher in the case of coating on steel substrate. Values of dry sliding friction coefficient between 0.58 and 0.79 were determined. It is to be noted, that there was also an increasing tendency towards a higher deposition speed. The friction coefficient of the clad on aluminum bronze substrate was in the range from 0.21 to 0.28 . Nevertheless, for both substrate materials no significant influence of powder particle size, the cladding speed and the remelting treatment on the friction coefficient was observed.

Figure 12 emphasizes the different resulting wear rates occurring by using several substrate materials. Indeed, the wear

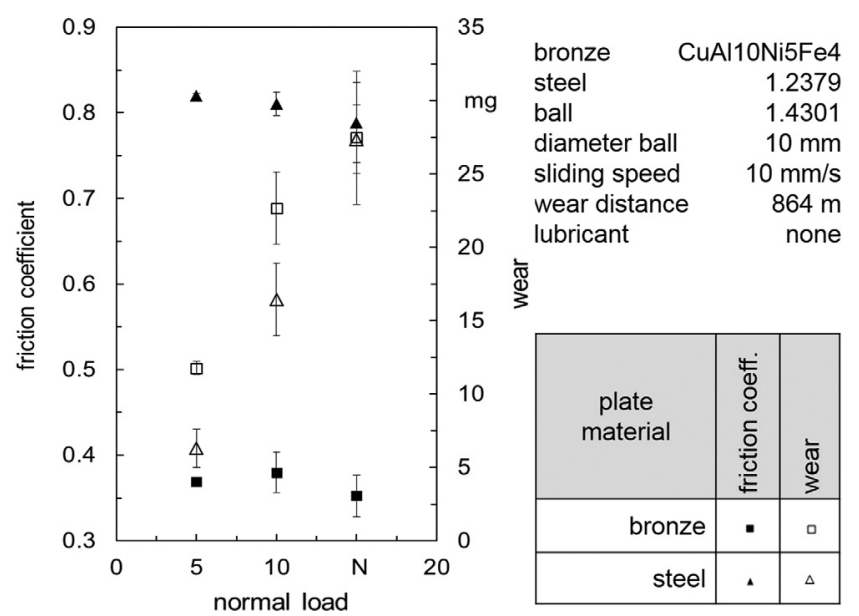

Figure 8. Influence of the normal load on the friction coefficient and wear in a dry oscillating ball-on-plate test.

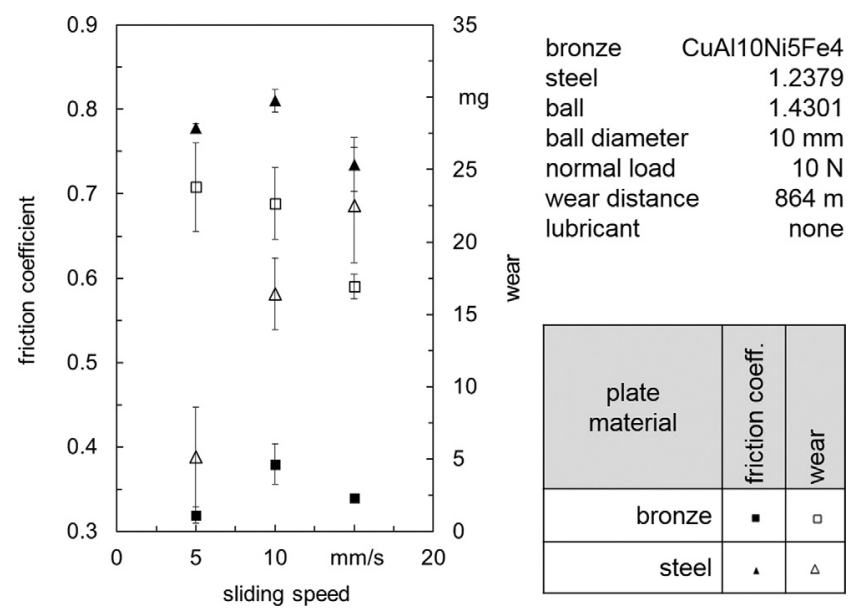

Figure 9. Influence of the sliding speed on the friction coefficient and wear in a dry oscillating ball-on-plate test.

of the clads was significantly decreased compared to the wear loss of the untreated substrate materials. The clads on aluminum bronze led to less wear in a range from $15.3 \mathrm{mg}$ to $12.3 \mathrm{mg}$. This was approximately $42 \%$ less compared to the results of the untreated substrate. Wear of the clads on steel in the range from $7.2 \mathrm{mg}$ to $2.5 \mathrm{mg}$ was observed. Compared to results of the untreated steel in dry-sliding, this was a reduction of wear of around $75 \%$. Furthermore, a decrease of wear with increasing process speed was observed. In the case of aluminum bronze substrate the influence of the powder particle size and remelting treatment on the wear could not be determined. However, it was observed that using larger particle size resulted in less wear when steel was used as substrate material.

\subsection{Metallographic analysis}

Metallographic cross sections were prepared to investigate the laser deposited tracks in terms of imperfections. There was 


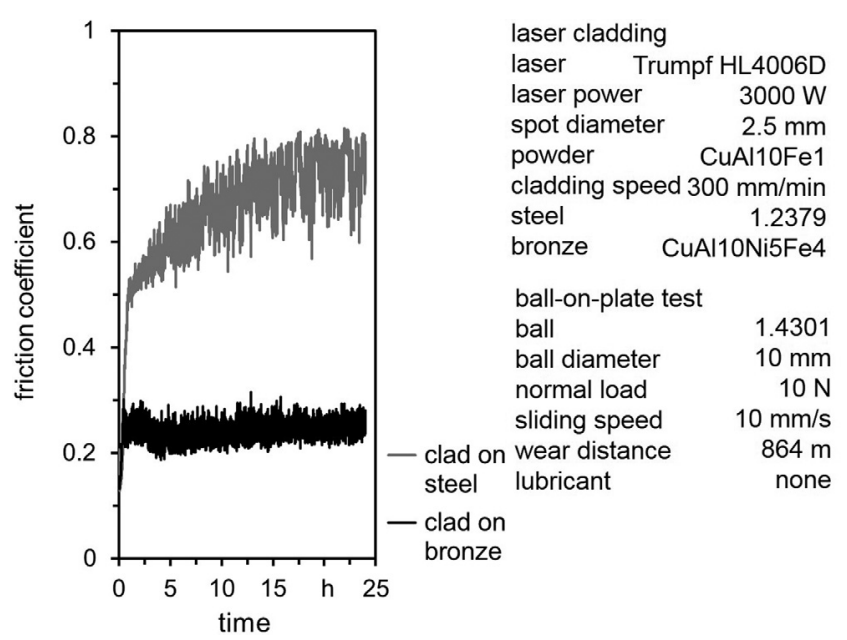

Figure 10. Examples of friction coefficient with respect to time and substrate material.

always a good bonding to the substrate. No cracks and pores could be detected in the clads. Figure 13 illustrates the hardness distribution across the interface of the cladding and substrate. Considerable hardness of approximately 670 HV0.5 was measured in the heat affected zone of the tool steel caused by the high cooling rate. The hardness in the heat affected zone of the aluminum bronze substrate amount to 352 HV0.5. In contrast, in the case aluminum bronze acted as substrate material, the hardness in the clad was higher by around $50 \%$.

By the metallographic cross section the formation of spherical grey particles in the clads were identified in the case of steel substrate. A metallographic cross section is given in Figure 14. Aluminum bronze was cladded on steel substrate with a cladding speed of $0.5 \mathrm{~m} / \mathrm{min}$, coarse powder was used and no remelting treatment was applied. Wavelength dispersive X-ray spectroscopy measurements (WDS) were carried out to show the chemical composition of the clad when steel acted as substrate material. The detail in Figure 14 is illustrating the area of two WDS measurements.

The first measurement (WDS 1) was executed in order to determine the chemical composition of these particles. Three measurements in three different particles were carried out. To determine an average value in the aluminum bronze matrix of the clad, the second measurement (WDS 2) was performed. Eleven WDS measurements were carried out in the middle of the clad from top to bottom. The distance between the measurement points amounted to $100 \mu \mathrm{m}$. The calibration of the X-ray spectroscopy was carried out on the steel substrate material and on the powder material. The average values of the WDS measurements for each area are given in Table 2. The reference data of the powder base on an inspection analysis by the manufacturer and the data of the steel composition represent the chemical composition according to the technical standard.

It was found out, that the chemical composition of the particles was close to that of the substrate. However, these particles were alloyed by $1 \%$ of aluminum and $7 \%$ of copper. Within the second WDS measurement it was established that

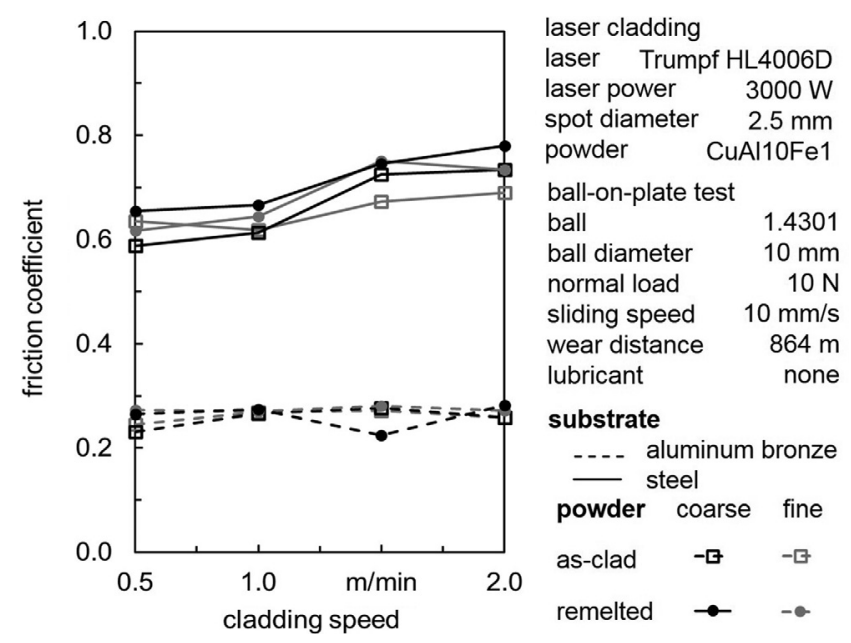

Figure 11. Influence of different cladding process parameters on the friction coefficient.

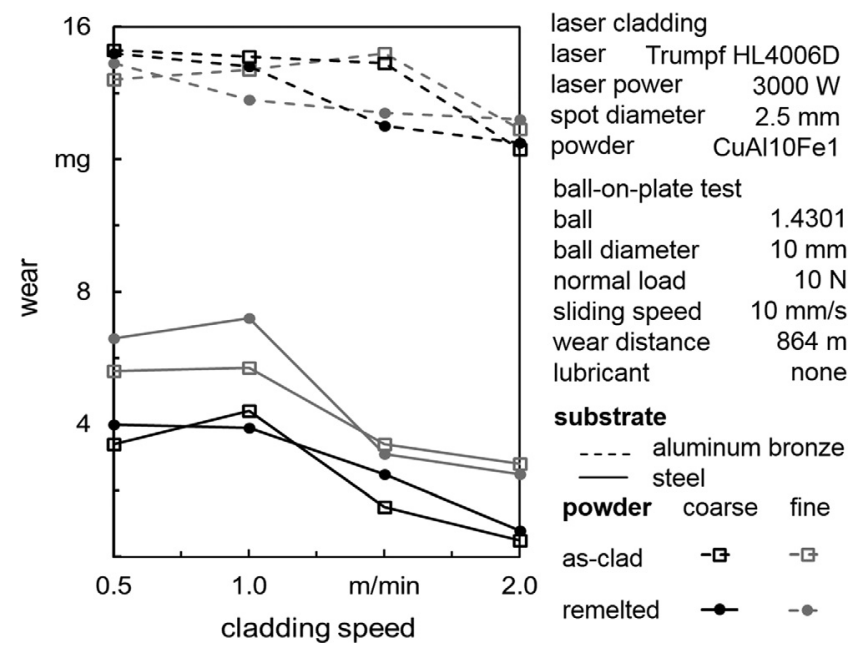

Figure 12. Influence of different cladding process factors on the wear.

the matrix of the clad was alloyed by iron of the steel substrate but not by other elements like chrome or carbon. Moreover, the aluminum content in the matrix was decreased from $10 \%$ to approximately $3 \%$. The content of copper was increased from $89 \%$ to about $93 \%$ and the content of iron was increased from $1 \%$ to $4 \%$. It was found that there was no difference in the chemical composition in the cladding matrix by comparing the results near the top, in the center and near the interface.

\section{Dry forming with an additively manufactured deep drawing tool}

To receive a low friction coefficient of the tool surface, the idea was developed to additively manufacture the entire deep drawing tool out of aluminum bronze. So, the tribological properties would not be negatively influenced by the steel substrate. Direct laser deposition was deployed to generate 


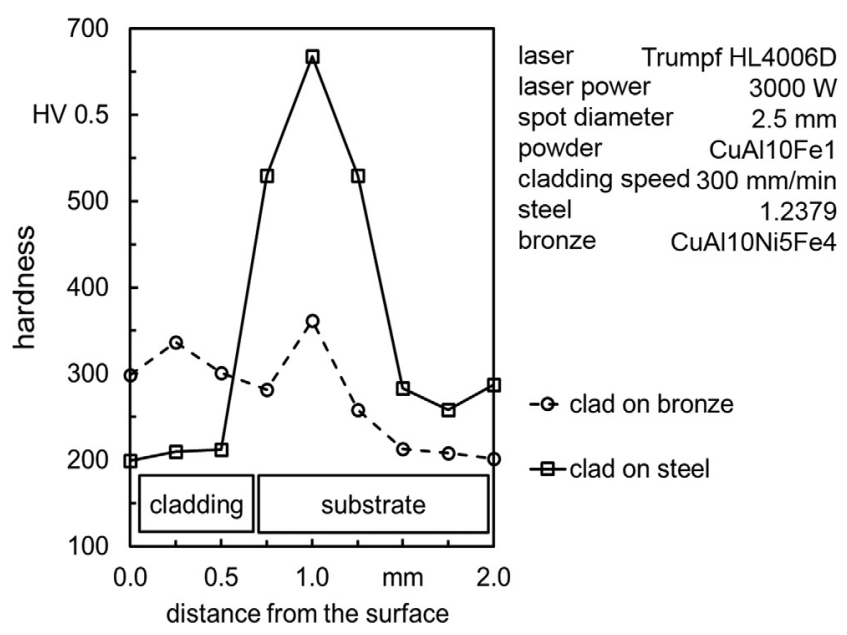

Figure 13. Illustration of the hardness distribution.

the near-net-shape geometries of the blank holder, the drawing die and the punch on aluminum bronze substrate. These parts are illustrated in Figure 15. The catchment efficiency was around $70 \%$.

By means of a metallographic picture in the center of the punch, the quality of the additively manufactured punch was investigated. No cracks were observed and just smaller pores with diameters up to $50 \mu \mathrm{m}$ were detected. Furthermore, hardness measurements were applied by three lines. The hardness was homogeneously distributed in the punch and an average value of $186.6 \mathrm{HV} 0.5$ with standard deviation of $9.8 \mathrm{HV} 0.5$ was measured (Figure 16).

Lubricated deep drawing experiments were carried out by variation of the blank holder force from $1.8 \mathrm{kN}$ to $2.9 \mathrm{kN}$ for examining the optimal blank holder force. The forming speed and the punch travel were kept constant for the deep drawing tests and the required punch force was measured. Using the calculated blank holder force of $2.3 \mathrm{kN}$ resulted in the formation of wrinkles. The formation of wrinkles could successfully be avoided by increasing the blank holder force to $2.9 \mathrm{kN}$, i.e. the blank holder pressure of $3.2 \mathrm{MPa}$. No cup base fractures were detected. In the case of using a higher blank holder force of $2.9 \mathrm{kN}$, a punch force of $25.4 \mathrm{kN}$ had to be applied. Furthermore, the deep drawing experiments were carried out without lubrication by using the same blank holder force of $2.9 \mathrm{kN}$. An example of a dry formed cup and the transient measurement data of the deep drawing process are given in Figure 17. A homogeneous shape of the transient measurement data of all forming processes was measured. The standard deviations were less than $1 \mathrm{kN}$. All formed cups neither showed cup base fractures nor formation of wrinkles. It is to be noted that the average of the maximum punch force was just about $5 \%$ higher when the forming process was carried out without lubrication compared to the lubricated forming process. However, the deep drawing tool is not yet applicable for industrial mass production because of low wear resistance.

\section{Discussion}

Increasing the cladding speed resulted in more dilution (Figure 5). Actually, a low dilution was assumed by applying higher cladding speed because the laser power was kept constant. That means the energy per unit length was lower. However, it was observed that the powder catchment efficiency was lower in the case of higher cladding speed caused by the lower energy per unit length. Because of the lower catchment efficiency more laser power transmitted through the powder into the substrate and caused the higher dilution. This effect was also revealed within applying higher laser power whereby the cladding speed kept constant (Figure 3). That means the energy per unit length was higher and actually more dilution was assumed. However, the dilution was not influenced by the higher energy per unit length because the powder catchment efficiency was increased.

The catchment efficiency, the dilution and the aspect ratio are indicators to assess the results of the laser cladding process. A high catchment efficiency of the cladding powder and a low dilution with the substrate material are preferable. Regarding an optimal aspect ratio, there are certain recommendations in the literature. The aspect ratio should amount between 3 and 3.7 [13], 4 [14] or 5 [15]. To receive a low dilution, in this work an optimal aspect ratio of 2 was determined. The result was qualitatively evaluated regarding a low amount of grey particles made of steel in the aluminum bronze clad as it can be seen in Figure 8. It should be noted that a low amount of grey particles in the clad was not always correlating to a low dilution which was quantitatively evaluated by the planimetry on the metallographic cross section as it is documented in Figure 3 to Figure 6.

At the beginning of dry oscillating ball-on-plate test the Hertzian stress was in a range of $119 \mathrm{MPa}$ and $565 \mathrm{MPa}$

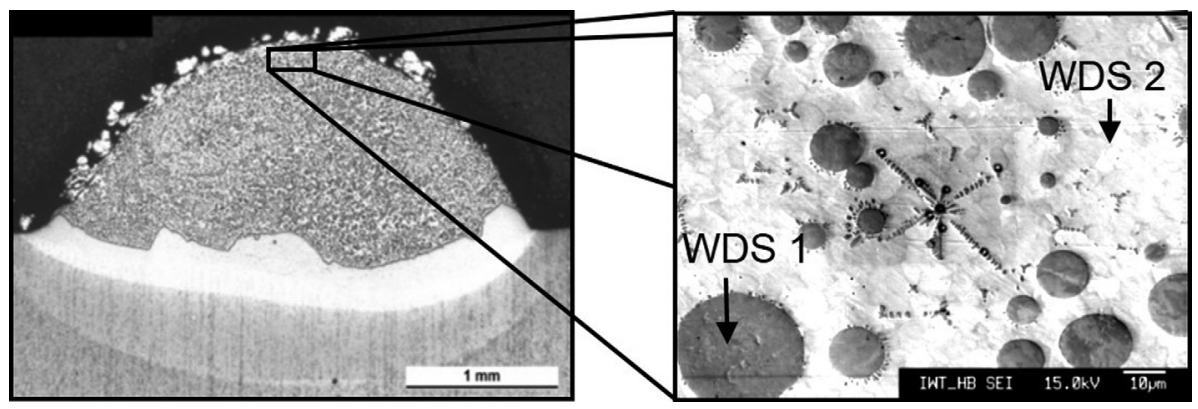

Figure 14. Metallurgical cross section. 
Table 2. Results of WDS-measurements, values in mass- $\%$.

\begin{tabular}{lccccccccc}
\hline & $\mathrm{Fe}$ & $\mathrm{V}$ & $\mathrm{Cr}$ & $\mathrm{Al}$ & $\mathrm{Mo}$ & $\mathrm{Cu}$ & $\mathrm{C}$ & $\mathrm{Si}$ \\
\hline WDS 1 & 76.486 & 0.572 & 11.241 & 1.069 & 0.783 & 7.086 & 1.960 & 0.346 & 0.396 \\
WDS 2 & 3.920 & 0.015 & 0.220 & 2.833 & 0.003 & 92.171 & 0.000 & 0.362 & 0.413 \\
Powder & 1.12 & 0 & 0 & 9.34 & 0 & 90.04 & 0 & 0 \\
Substrate & 84.35 & 84.35 & 12 & 0 & 0.7 & 0 & 0 & 1.55 & 0.3 \\
\hline
\end{tabular}

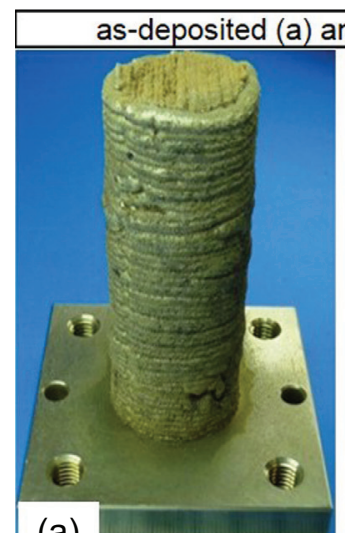

(a)
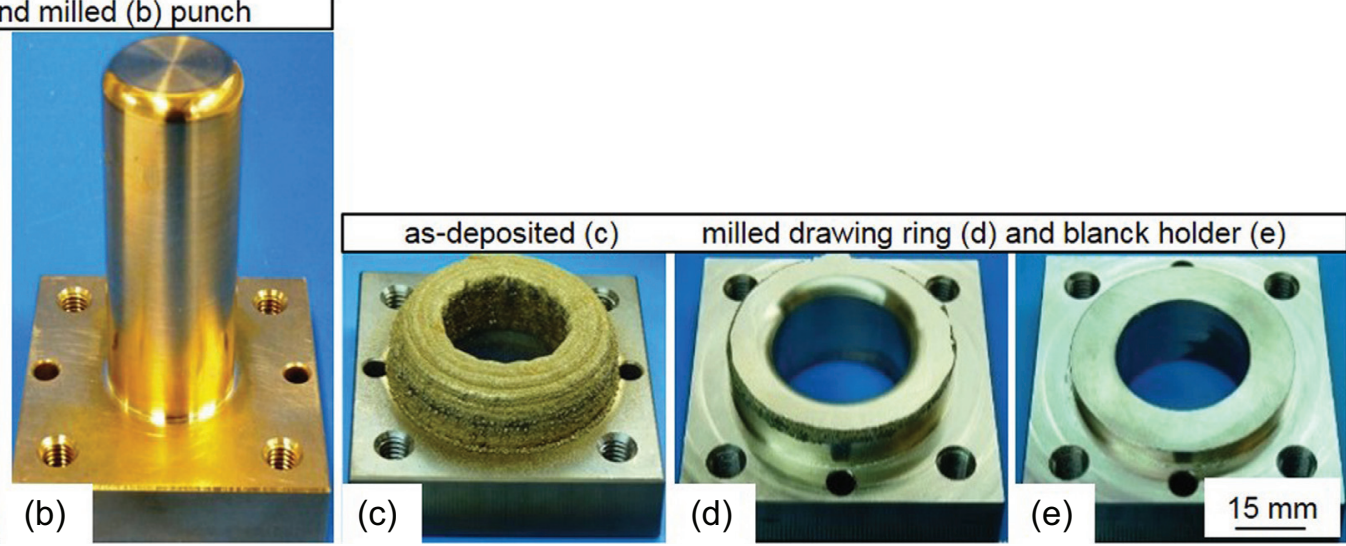

Figure 15. Additively manufactured and milled deep drawing tool.

depending on the normal force and the plate material. These values are partially higher compared to the arising surface pressures in a deep drawing process. Simulative studies of a deep drawing process to form circular cups out of 1.4301 revealed that the values of pressures at the draw ring radius amounted between $100 \mathrm{MPa}$ and $200 \mathrm{MPa}$. Significant high pressure in the area of the drawing radius could amount to $400 \mathrm{MPa}$ [16]. The resulting surface pressures at the end of the ball-on-plate test were in a range from $0.75 \mathrm{MPa}$ to $1.25 \mathrm{MPa}$. This values are significantly lower compared to surface pressure in other investigations. At the end of the ball-on-disc test the resulting surface pressure was $600 \mathrm{MPa}$ [16]. It is to be mentioned that the ball-on-plate test is a simplified experiment for the comparison of the behaviour of materials or surfaces. To receive an accurate evidence of the tribological behaviour of the surface, therefore, in subsequent investigations deep drawing tests are going to be applied.

The tribological tests on clads revealed that the results were mainly influenced by the substrate material. Within the determination of a process window for cladding aluminum bronze on steel, it was observed that applying higher cladding speed resulted in more dilution. A maximal cladding speed of $0.7 \mathrm{~m} / \mathrm{min}$ was applied. Particular, in the dry oscillating ball on plate test specimens were tested which were cladded with a speed of $2 \mathrm{~m} / \mathrm{min}$. Hence, more dilution and a higher influence on the tribological behaviour was assumed because of the higher cladding speed. However, there was no significant influence of the cladding speed on the tribological behaviour of the clads. In comparison to the results of the tribological reference tests on the untreated steel and bronze substrate, the results of the claddings in dry sliding shifted to lower values. Furthermore, the results both of the untreated substrates

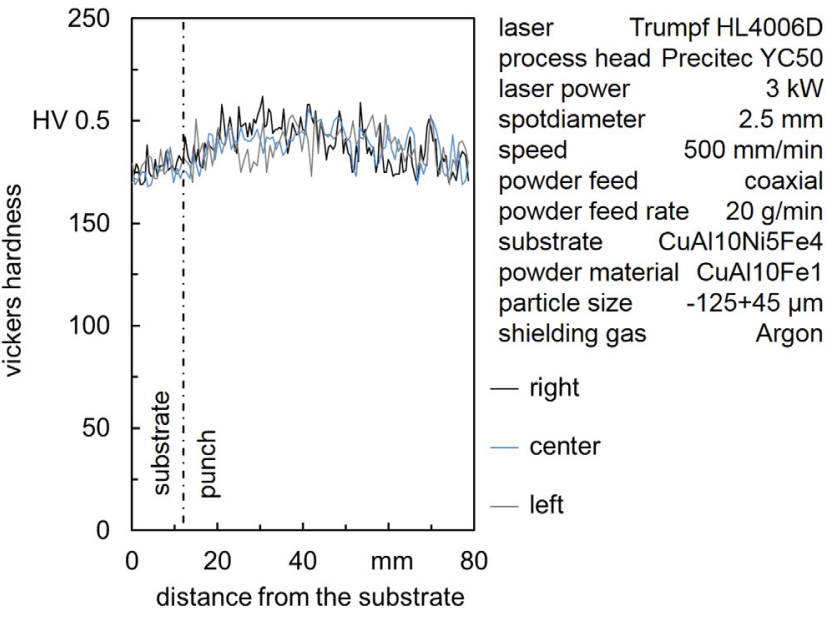

Figure 16. Hardness distribution in the punch.

and the claddings showed similar tendencies. Higher wear and lower friction coefficient were found in the case of aluminum bronze substrate and the opposite behaviour in the case of steel substrate. Indeed, it becomes apparent that the particular chemical composition of the aluminum bronze clads on steel led to significantly less wear during dry sliding against 1.4301. These results of the aluminum bronze clads on the bronze substrate are in accordance to the performance in prior investigations using the tribometer and test parameters. In these studies, a friction coefficient in the range from 0.2 to 0.3 was determined. The same aluminum bronze was cladded. However, aluminum alloy 6082 acted as a substrate material and $\mathrm{Si}_{3} \mathrm{~N}_{4}$ ball was the counter body [11]. 


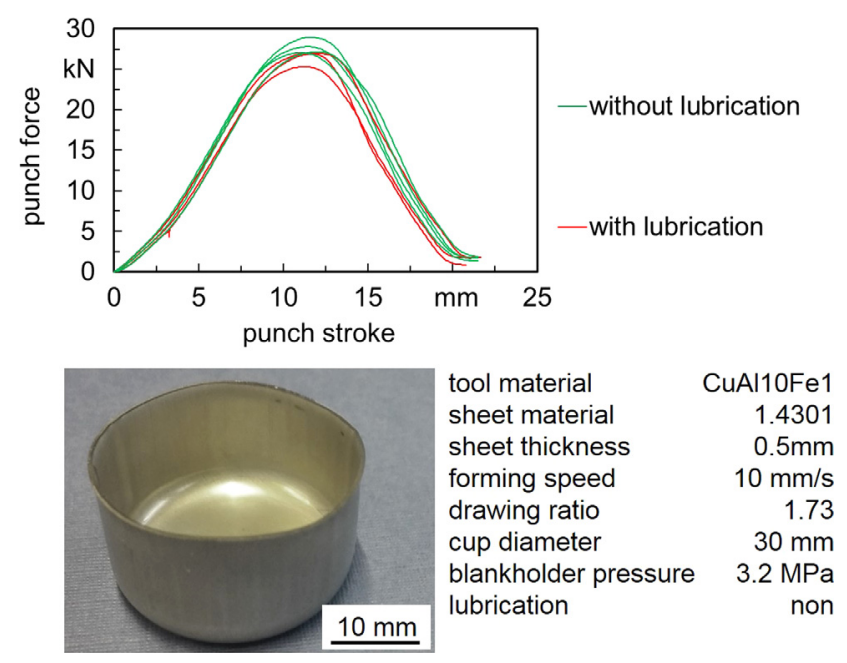

Figure 17. Results of the deep drawing test with and without lubricant (a) and example of a dry formed cup (b).

To understand the influence of the steel substrate on the tribological behaviour, WDS measurements were carried out in the aluminum bronze clads on steel. Despite of complete miscibility in the liquid phase within the binary system of copper and iron, grey spherical particles were detected in the clads on steel substrate. The formation of these particles indicated a liquid phase separation. By the WDS measurements in these particles, it was found out that they had almost the same chemical composition as the steel substrate. Only the content of carbon was higher. This finding supports the assumption, that the higher carbon content caused the liquid separation of copper and iron during the cladding process [17]. Furthermore, usually high hardness would be expected in these particles out of steel. Because of the chemical composition, commonly martensitic transformation is observed as a result of the high cooling rate during welding applications on this cold work steel. This effect is illustrated in Figure 13. In the heat affected zone a hardness of around 670 HV0.5 was achieved. By the WDS measurements in the particles a high content of copper was detected. The content of copper in the particles of around $7 \%$ was close to the solubility of copper in $\gamma$-iron [17]. It may be assumed that with this, austenite was stabilized at room temperature. Therefore, the particles in the clads did not transform into martensite despite the high cooling rate of the cladded tracks. Consequently, no higher hardness values in the particles were achieved as in the heat affected zone. In addition, not only the particles in the clads but also the copper matrix showed lower hardness compared to the clads on aluminum bronze substrate. It can be assumed, that this was caused by the lower aluminum content which was determined by the WDS measurement. Lower content of aluminum in aluminum bronze decrease the hardness [18].

A deep drawing tool set was additively manufactured by direct laser deposition. The hardness was homogeneously distributed in the punch. Because of the heat accumulation, no high cooling rates could be realized and hence, no higher hardness could be achieved. An average hardness value of
186 HV0.5 was measured in the punch (Figure 16). In contrast, in the case of aluminum cladding on aluminum bronze substrate, the hardness in the track amounted to 300 HV0.5 (Figure 13).

\section{Conclusions}

To receive a low dilution, it was evaluated that a lower dilution could be realized by increasing the powder feed rate or applying a lower cladding speed. On the other hand this resulted in a smaller aspect ratio. It can be concluded that it had to be compromised between a high aspect ratio of the cladded tracks or a low dilution. However, the quality of the clads should be evaluated by means of metallographic analyses. Besides a low dilution measured by planimetry a mixing of steel in the bronze clad was observed because of a liquid phase separation of the copper alloy and the steel substrate. Within this work, the question was discussed in how far the substrate had an influence on the properties of the aluminum bronze clads. It is concluded that the tribological dry sliding behaviour of the cladded tracks were mainly influenced by the substrate material and could not be influenced by other process parameters. The knowledge about the correlation between the cladding process of aluminum bronze on steel 1.2379 and the behaviour in lubricant-free sliding tests is helpful to generate deep drawing tools for dry metal forming in the future.

Acknowledgements. This work was supported by Deutsche Forschungsgemeinschaft (DFG) within priority program SPP 1676 and the project $\mathrm{Se} 1435 / 21$.

\section{References}

1. F. Vollertsen, F. Schmidt, Int. J. Precis. Eng. Manuf. Green Tech. 1 (2014) 59-62.

2. F. Klocke, D. Trauth, P. Mattfeld, A. Shirobokov, K. Bobzin, T. Brögelmann, S. Bastürk, Dry Met Forming OAJFMT 1 (2015) 11-16.

3. W.S. Li, Z.P. Wang, Y.H. Lu, Y.H. Yuan, F. Wang, Wear 261 (1996) 130-136.

4. L.L. Gao, X.H. Cheng, Wear 265 (2008) 986-991.

5. M. Demiral, D. Ozyurek, M. Unal, Ind. Lubr. Tribol. 61 (2009) 40-46.

6. Z. Shi, A. Bloyce, Y. Sun, T. Bell, Wear 198 (1996) 300-306.

7. B.K. Prasad, Wear, 257 (2004) 110-123.

8. Y. Li, L. Ngai, Wear 197 (1996) 130-136.

9. M. Schmidt, R. Kolleck, A. Grimm, R. Veit, K. Bartkowiak, CIRP Ann.-Manuf. 59 (2010) 211-214.

10. H. Wang, Z. Wang, Y. Lu, Y. Li, G. Tian, Adv. Mater. Res. 148149 (2011) 621-627.

11. M. Schwander, D. Füller, H. Köhler, F. Feuerhahn, M. Dias da Silva, M. Prieske, F. Vollertsen, Prod. Eng. Res. Devel. 8 (2014) 603-611.

12. GFT e.V, Arbeitsblatt 7 Tribologie, 2002, 44.

13. Y. Liu, J. Mazumder, K. Shibata, Metall. Mater. Trans. 25B (1994) 749-759. 
14. G. Backes, E.W. Kreutz, R. Jung, A. Gebhardt, Euro Laser 1 (1996) 44-48.

15. W.M. Steen, Laser surface cladding, Proceedings of the Indo US - Workshop on Principles of Solidification and Materials Processing, SOLPROS, 1988, pp. 163-178.
16. Ch.J. Kuwer, Ph.D. thesis, RWTH Aachen (2007) 37-89.

17. M. Hansen, in Constitution of binary alloys, 2nd edn. (Metallurgy and Metallurgical Engineering Series) McGrawHill, 1958, pp. 580.

18. P. Brezina, International Metals Review 27 (1982) 77-120.

Cite this article as: Freiße H, Langebeck A, Köhler H, Seefeld T \& Vollertsen F: Investigations on dry sliding of laser cladded aluminum bronze. Manufacturing Rev. 2016, 3, 13. 